\title{
Variations in ${ }^{123}$ I-metaiodobenzylguanidine (MIBG) late heart mediastinal ratios in chronic heart failure: a need for standardisation and validation
}

\author{
Hein J. Verberne • Jan B. A. Habraken • \\ Berthe L. F. van Eck-Smit • Denis Agostini • \\ Arnold F. Jacobson
}

Received: 16 July 2007 / Accepted: 15 September 2007 / Published online: 6 October 2007

(C) Springer-Verlag 2007

\begin{abstract}
Background There is lack of validation and standardisation of acquisition parameters for myocardial ${ }^{123}$ I-metaiodobenzylguanidine (MIBG). This lack of standardisation hampers large scale implementation of ${ }^{123} \mathrm{I}-\mathrm{MIBG}$ parameters in the evaluation of patients with chronic heart failure (CHF). Methods In a retrospective multi-centre study ${ }^{123}$ I-MIBG planar scintigrams obtained on 290 CHF patients $(82 \%$ male; $58 \%$ dilated cardiomyopathy; New York Heart Association [NYHA classification] > I) were reanalysed to determine the late heart-to-mediastinum ratio $(\mathrm{H} / \mathrm{M})$.

Results There was a large variation in acquisition parameters. Multivariate forward stepwise regression showed that a significant proportion $(31 \%, p<0.001)$ of the variation in late $\mathrm{H} / \mathrm{M}$ could be explained by a model containing patientrelated variables and acquisition parameters. Left ventricular ejection fraction $(p<0.001)$, type of collimation $(p<0.001)$,
\end{abstract}

H. J. Verberne - J. B. A. Habraken • B. L. F. van Eck-Smit Department of Nuclear Medicine, Academic Medical Center, University of Amsterdam,

Amsterdam, The Netherlands

D. Agostini

Department of Nuclear Medicine, CHU Cote de Nacre,

Caen, France

A. F. Jacobson

GE Healthcare,

Princeton, NJ, USA

H. J. Verberne $(\bowtie)$

Department of Nuclear Medicine,

Academic Medical Center, F2-238,

P.O.Box 22700, 1100 DE Amsterdam, The Netherlands

e-mail: h.j.verberne@amc.uva.nl acquisition duration ( $p=0.001)$, NYHA class $(p=0.028)$ and age $(p=0.034)$ were independent predictors of late $\mathrm{H} / \mathrm{M}$. Conclusions Acquisitions parameters are independent contributors to the variation of semi-quantitative measurements of cardiac ${ }^{123}$ I-MIBG uptake. Improved standardisation of cardiac ${ }^{123}$ I-MIBG imaging parameters would contribute to increased clinical applicability for this procedure.

Keywords Heart failure - Instrumentation · MIBG ·

Prognosis

\section{Introduction}

Radiolabelled metaiodobenzylguanidine ( ${ }^{123} \mathrm{I}-\mathrm{MIBG}$ ), an analog of the false neurotransmitter guanethidine, localises in adrenergic nerve terminals primarily via the norepinephrine (NE) transporter (uptake-1) system [1, 2]. In the past two decades, a large number of investigators have demonstrated decreased myocardial ${ }^{123}$ I-MIBG uptake in heart failure patients and have shown that those with the lowest uptake tend to have the poorest prognosis [3-11]. There have also been findings suggesting that abnormalities of myocardial ${ }^{123}$ I-MIBG uptake may be predictive of increased risk for ventricular arrhythmia and sudden cardiac death (SCD) $[12,13]$.

One factor that has constrained acceptance of cardiac ${ }^{123}$ I-MIBG imaging as a clinical patient management tool in heart failure has been the variability of technical aspects of the procedure. Although most publications have included the heart-to-mediastinum ratio $(\mathrm{H} / \mathrm{M})$ as the measure of myocardial uptake, the methods used to obtain this parameter show considerable variation. In addition, the influence of procedural and acquisition parameters on the 
reproducibility of this measurement technique have only occasionally been considered. While the effect of collimator selection on $\mathrm{H} / \mathrm{M}$ ratios has been studied, similar attention has not been paid to the impact of administered activity, acquisition time and duration [14]. Given the absence of published guidelines for cardiac ${ }^{123}$ I-MIBG imaging, standardisation of procedures among individual users of this agent becomes even more important.

The objective of the present study was to examine the influence of procedural variables associated with ${ }^{123} \mathrm{I}-$ MIBG imaging when a standardised technique was used to determine the $\mathrm{H} / \mathrm{M}$ ratio.

\section{Materials and methods}

\section{Study design}

Myocardial ${ }^{123}$ I-MIBG scintigrams on 290 heart failure patients (male and female subjects $\geq 18$ years of age with New York Heart Association [NYHA] Classes II-IV) from six sites in five European countries were retrieved and analysed. These imaging studies were performed between 1993 and 2002 and were collected for a previously described trial [15]. This trial was designed to show that standardised methodology could be applied to the analysis and processing of ${ }^{123}$ I-MIBG myocardial images to obtain reproducible quantitative results. As the large majority of patients had only late planar ${ }^{123}$ I-MIBG images, the analysis of these images is the sole focus of this paper.
Investigational sites sent copies of all digital image files to an Imaging Core Laboratory (ICL) for evaluation and analysis. Data on amount of ${ }^{123}$ I-MIBG activity injected and image acquisition parameters (i.e. delay after injection of ${ }^{123}$ I-MIBG and start of acquisition, acquisition duration and type of collimator used) were collected.

The primary efficacy objective of the original trial was to determine the prognostic significance of the late $\mathrm{H} / \mathrm{M}$ ratio in relation to occurrence of major cardiac events (MCE), defined as either: 1) cardiac death due to all causes, including myocardial infarction (MI), progressive heart failure and sudden cardiac death (SCD); 2) cardiac transplant; 3) potentially fatal arrhythmic event, including resuscitated cardiac arrest or appropriate internal cardiac defibrillator (ICD) discharge. Results of that analysis have been published. For the purposes of this paper, $\mathrm{H} / \mathrm{M}$ thresholds associated with low-, intermediate- and high-risk for MCEs were defined to provide the basis for the multivariate analysis described below.

Image analysis

An experienced nuclear medicine technologist not affiliated with the ICL processed all the planar images to determine the heart/mediastinum $(\mathrm{H} / \mathrm{M})$ ratio. The heart region of interest (ROI) was drawn manually to include both ventricles and any atrial activity that was clearly visible. A square mediastinal ROI was drawn in the upper mediastium, using the apices of the lungs as anatomic landmarks (Fig. 1). The H/M ratio was calculated as the ratio of the counts/pixel in the two ROIs.
Fig. 1 Example of processing procedure for late planar ${ }^{123}$ I-MIBG images. The positioning of the mediastinal ROI was standardized in relation to the lung apex, the lower boundary of the upper mediastinum and the midline between the lungs

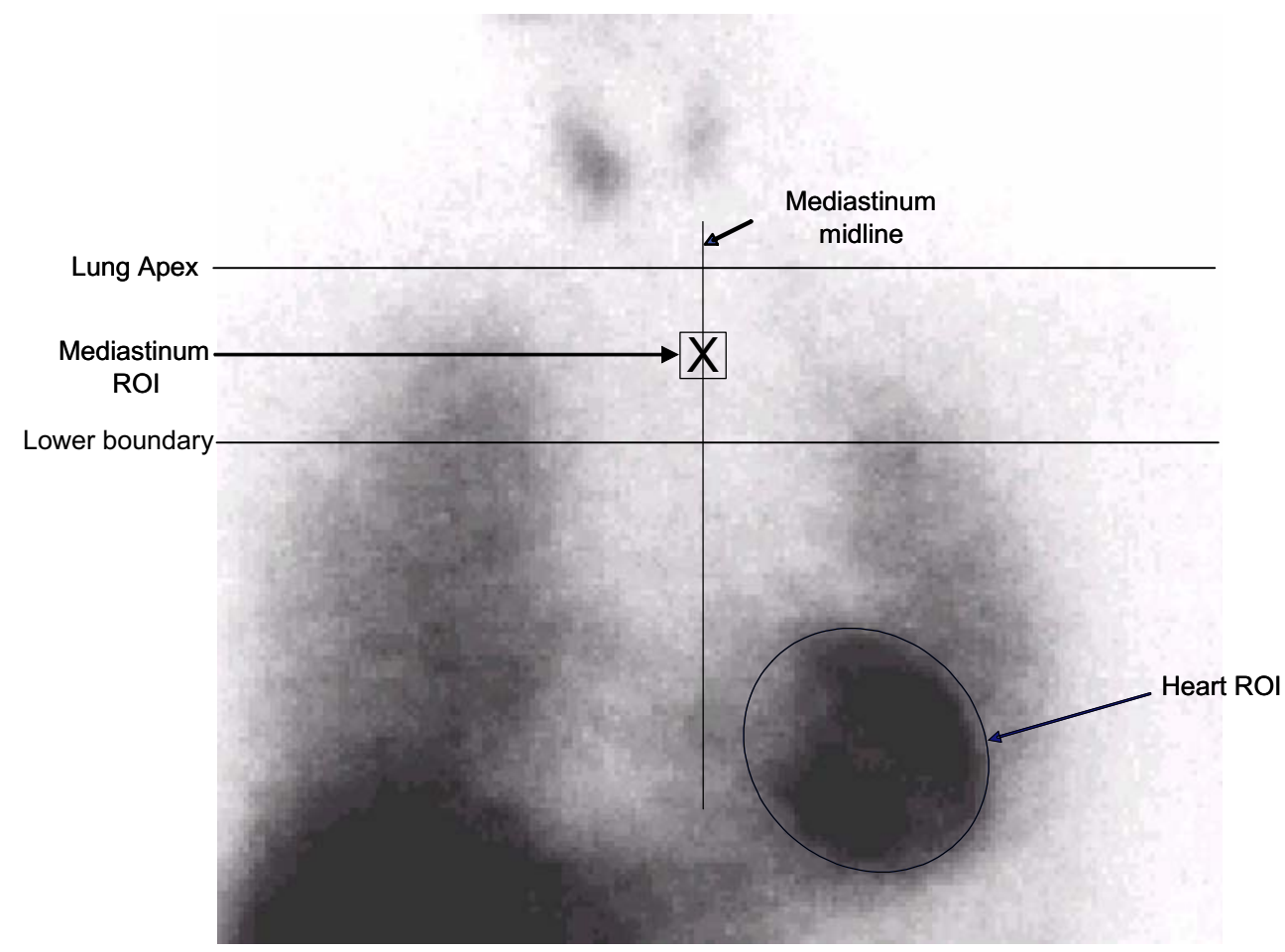


Statistical analysis

Data are presented as mean \pm standard deviation, unless indicated otherwise. Kaplan-Meier survival analysis and the log-rank test were used to analyse differences in event rate for different subject groups defined by the late $\mathrm{H} / \mathrm{M}$ thresholds. Differences between these groups for continuous data were compared using analysis of variance (ANOVA) with a post hoc Bonferroni. Categorical data were compared using the Fisher's exact test. A forward stepwise multivariate regression analysis was performed to determine independent predictors of late $\mathrm{H} / \mathrm{M}$. Explanatory variables were related to patient characteristics (i.e. gender, age, NYHA class, left ventricular ejection fraction [LVEF], and underlying etiology of heart failure) and to acquisition parameters (i.e. amount of injected ${ }^{123}$ I-MIBG activity, collimator type, delay after injection and start of acquisition, and duration of acquisition). Multivariate forward stepwise regression analysis was performed for all study subjects. The overall goodness-of-fit for each model was expressed as the adjusted $R^{2}$. The $F$ test was used to assess whether a model explained a significant proportion of the variability. A $p<0.05$ was considered to indicate a statistically significant difference. All statistical analyses were performed with SPSS (SPSS for Windows, version 11.01, SPSS Inc, Chicago, IL, USA).

\section{Results}

As previously described, there were 67 major cardiac events. Figure 2 shows a Kaplan-Meier survival analysis for three different groups of late $\mathrm{H} / \mathrm{M}$. Quantitative estimates for low risk (late $\mathrm{H} / \mathrm{M}>2.0$, 2-year survival of $95 \%$ ), intermediate risk (late H/M 1.4-2.0, 2-year survival of 76\%) and high risk (late $\mathrm{H} / \mathrm{M}<1.4$, 2-year survival of $45 \%$ ) could be determined. The differences in event rate were statistically significant between the three groups (all $p<0.001$ ).

Table 1 shows the baseline characteristics and the parameters related to the ${ }^{123} \mathrm{I}-\mathrm{MIBG}$ acquisition of all subjects and for the three different groups of late $\mathrm{H} / \mathrm{M}$. Overall, the majority of subjects were male and were in functional class II according the NYHA classification and had a LVEF $<50 \%(n=262)$. Between the three late $\mathrm{H} / \mathrm{M}$ groups, there were differences in age (subjects with a late $\mathrm{H} / \mathrm{M}>2.0$ were younger), NYHA classification, LVEF (increasing from subjects with a late $\mathrm{H} / \mathrm{M}<1.4$ to subjects with a late $\mathrm{H} / \mathrm{M}>2.0$ ) and $\mathrm{HF}$ etiology. In addition, there were no differences in parameters of heart failure (LVEF and NYHA classification) between the different centres.

Overall, most acquisitions were performed with lowenergy high-resolution (LEHR) collimators (74\%), followed by low-energy general purpose (LEGP) collimators

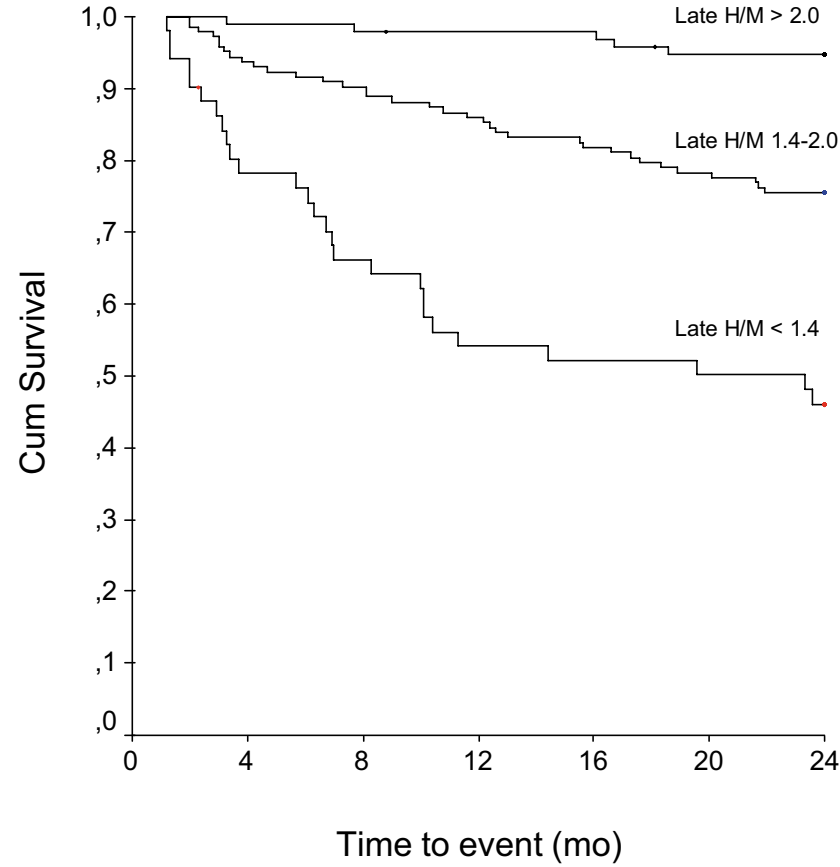

Fig. 2 Kaplan-Meier curve showing the relation between survival and time to first major cardiac event for three groups with different $\mathrm{H} / \mathrm{M}$ values: late $\mathrm{H} / \mathrm{M}<1.4$ vs late $\mathrm{H} / \mathrm{M} 1.4-2.0, p<0.0001$; late $\mathrm{H} / \mathrm{M}<1.4$ vs late $\mathrm{H} / \mathrm{M}>2.0, p<0.0001$; late $\mathrm{H} / \mathrm{M} 1.4-2.0$ vs late $\mathrm{H} / \mathrm{M}>2.0, p<0.0001$

(17\%). Only $9 \%$ of acquisitions were made with mediumenergy (ME) collimators, all from one centre. The amount of activity injected ranged from 72 to $370 \mathrm{MBq}$ (mean 164 $53 \mathrm{MBq}$ ). There was a large variation in the time-span after between injection of ${ }^{123} \mathrm{I}$-MIBG and imaging, ranging from 1.9 up to $6.9 \mathrm{~h}$ (mean delay $4.3 \pm 0.6 \mathrm{~h}$ ). The duration of acquisition could be classified in seven categories: 1, 2, 3, 4, 5, 10 and $15 \mathrm{~min}$. The majority of acquisitions was performed with a 10 -min duration $(n=203)$. There were differences between the three late $\mathrm{H} / \mathrm{M}$ groups in collimator type, amount of injected ${ }^{123} \mathrm{I}-\mathrm{MIBG}$, delay after injection, and duration of acquisition (Table 1).

Table 2 shows the results of the stepwise multivariate regression analysis for all subjects and all parameters. LVEF, collimator type, duration of acquisition, NYHA classification and age were independent predictors of late $\mathrm{H} / \mathrm{M}$. This model predicted approximately $30 \%$ of the variation in late $\mathrm{H} / \mathrm{M}$ results $(p<0.0001)$. Even after exclusion of the very low acquisition durations $(<5 \mathrm{~min})$, the duration of acquisition remained an independent predictor of late $\mathrm{H} / \mathrm{M}$.

In subjects with a late $\mathrm{H} / \mathrm{M}<1.4$, stepwise multivariate regression analysis showed that NYHA classification and delay after injection were the only independent predictors of late $\mathrm{H} / \mathrm{M}$ (Table 3). This model predicted approximately $10 \%$ of late $\mathrm{H} / \mathrm{M}(p=0.03)$. In subjects with a late H/M 1.42.0, stepwise multivariate regression analysis showed that 
Table 1 Patient and scintigraphic parameters for all subjects and subdivided by late $\mathrm{H} / \mathrm{M}{ }^{123} \mathrm{I}-\mathrm{MIBG}$

\begin{tabular}{|c|c|c|c|c|}
\hline & \multirow[t]{2}{*}{ All $(N=290)$} & \multicolumn{3}{|l|}{ Late $\mathrm{H} / \mathrm{M}$} \\
\hline & & $<1.4(N=51)$ & $1.4-2.0(N=143)$ & $>2.0(N=96)$ \\
\hline \multicolumn{5}{|l|}{ Patient characteristics } \\
\hline Male/Female & $237 / 53$ & $39 / 12^{*}$ & $117 / 26^{*}$ & $81 / 15^{*}$ \\
\hline Age (years) & $53 \pm 11(21-83)$ & $55 \pm 10 \dagger$ & $54 \pm 10 \ddagger$ & $49 \pm 11$ \\
\hline NYHA (II/III/IV) & $165 / 116 / 9$ & $11 / 34 / 6 \dagger$ & $85 / 55 / 3 \dagger$ & $69 / 27 / 0 \dagger$ \\
\hline LVEF $(\%)$ & $32 \pm 14(7-85)$ & $23 \pm 9 \dagger$ & $31 \pm 13 \hbar$ & $39 \pm 14^{*}$ \\
\hline Etiology of heart failure (isch/non-isch) & $121 / 169$ & $20 / 31 \ddagger$ & $70 / 73 \ddagger$ & $31 / 65 t$ \\
\hline \multicolumn{5}{|l|}{ Scintigraphic parameters } \\
\hline Collimator type (LEGP/LEHR/ME) & $50 / 216 / 24 \dagger$ & $24 / 25 / 2 \dagger$ & $24 / 104 / 15 \dagger$ & $2 / 87 / 7 \dagger$ \\
\hline Activity (MBq) & $164 \pm 53(72-370)$ & $145 \pm 31 \dagger$ & $173 \pm 64$ & $160 \pm 41$ \\
\hline Delay after injection (h) & $4.3 \pm 0.6(1.9-6.9)$ & $4.1 \pm 0.5 \ddagger$ & $4.3 \pm 0.5 t$ & $4.5 \pm 0.6$ \\
\hline Duration of acquisition (min) & $9.6 \pm 3.3(1-15)$ & $11.3 \pm 4.3 \dagger$ & $9.2 \pm 3.4$ & $9.4 \pm 2.0^{*}$ \\
\hline
\end{tabular}

Data are presented as mean \pm standard deviation (range).

NYHA New York Heart Association, LVEF left ventricular ejection fraction, Isch ischemic, Non-isch non-ischemic, LEGP low-energy all purpose, $L E H R$ low-energy high resolution, $M E$ medium energy, $M B q$ mega-Becquerel, $h$ hours, min minutes.

Categorical data (Fisher's exact test, for each group): ${ }^{*} p=0.53 ; \dagger p<0.001 ; \ddagger p<0.035$.

Continuous data (ANOVA with posthoc Bonferoni): ${ }^{*} p<0.01$ compared to late $\mathrm{H} / \mathrm{M}<1.4 ; \dagger p<0.01$ compared to late $\mathrm{H} / \mathrm{M} 1.4-2.0 ; \ddagger p<0.01$ compared to late $\mathrm{H} / \mathrm{M}>2.0$.

LVEF and collimator type were the only independent predictors of late $\mathrm{H} / \mathrm{M}$ (Table 4). This model predicted approximately $10 \%$ of late $\mathrm{H} / \mathrm{M}(p=0.001)$. In subjects with a late $\mathrm{H} / \mathrm{M}>2.0$, duration of acquisition was the only independent predictor of late $\mathrm{H} / \mathrm{M}$ (Table 5). However, duration of acquisition predicted only $1 \%$ of late $\mathrm{H} / \mathrm{M}$ and explained a statistically non-significant proportion of variability $(p=0.347)$.

\section{Discussion}

In a heterogeneous population of heart failure patients, the most important determinant of cardiac uptake of ${ }^{123}$ I-MIBG is the degree of impairment of the NE transporter function in presynaptic adrenergic neurons [3-11]. As such, considerable variation in late $\mathrm{H} / \mathrm{M}$ would be expected between patients with otherwise similar clinical presentations (NYHA class, LVEF, etc). Nevertheless, the findings of

Table 2 Multivariate analysis of clinical and acquisition related parameters as predictors of late $\mathrm{H} / \mathrm{M}$ for all subjects $(N=290)$

\begin{tabular}{llll}
\hline Variables & Coefficient $b$ & Standard error $b$ & $P$ value \\
\hline Constant & 0.549 & 0.411 & \\
LVEF & 0.015 & 0.02 & $<0.001$ \\
Collimator type & 0.531 & 0.087 & $<0.001$ \\
$\begin{array}{l}\text { Duration of } \\
\text { acquisition }\end{array}$ & 0.045 & 0.014 & 0.001 \\
NYHA & -0.121 & 0.055 & 0.028 \\
Age & -0.006 & 0.003 & 0.034 \\
\hline
\end{tabular}

Goodness-of-fit of the model: adjusted $R^{2}=0.312 ; P$ value $=<0.0001$ the present study indicate that a proportion of the variation in the late $\mathrm{H} / \mathrm{M}{ }^{123} \mathrm{I}-\mathrm{MIBG}$ can also be explained by differences in acquisition parameters. Of particular interest, the factors contributing to this variation differed for different ranges of late $\mathrm{H} / \mathrm{M}$.

Abnormalities in myocardial ${ }^{123}$ I-MIBG imaging have been demonstrated in patients with both common cardiac pathologies such as $\mathrm{CAD}, \mathrm{CHF}$, and non-ischemic cardiomyopathy [3-12, 16-18] and more uncommon entities such as Syndrome X [19], Brugada Syndrome [20] and idiopathic ventricular fibrillation [13]. However, there has been limited standardisation of the acquisition and quantitative analysis techniques used by various investigators, and most studies have involved small numbers of subjects and locally defined reference standards and measures of outcome. Thus, despite the large number of studies on cardiac ${ }^{123} \mathrm{I}$ MIBG imaging, these methodological and analytical limitations have hampered the implementation of this technique for the evaluation and management of individual patients.

Acquisition duration was one of the independent predictors of late $\mathrm{H} / \mathrm{M}$. The positive correlation suggests that a longer acquisition time is associated with a higher

Table 3 Multivariate analysis of clinical and acquisition related parameters as predictors of late $\mathrm{H} / \mathrm{M}$ for subjects with a late $\mathrm{H} / \mathrm{M}<1.4$ $(N=51)$

\begin{tabular}{llll}
\hline Variables & Coefficient $b$ & Standard error $b$ & $P$ value \\
\hline Constant & 1.680 & 0.161 & \\
NYHA & -0.055 & 0.027 & 0.049 \\
Delay after injection & -0.068 & 0.030 & 0.031 \\
\hline
\end{tabular}

Goodness-of-fit of the model: adjusted $R^{2}=0.104 ; P$ value $=0.030$ 
Table 4 Multivariate analysis of clinical and acquisition related parameters as predictors of late $\mathrm{H} / \mathrm{M}$ for subjects with a late $\mathrm{H} / \mathrm{M} 1.4$ $2.0(N=143)$

\begin{tabular}{llll}
\hline Variables & Coefficient $b$ & Standard error $b$ & $P$ value \\
\hline Constant & 1.370 & 0.078 & \\
LVEF & 0.004 & 0.001 & 0.001 \\
Collimator type & 0.086 & 0.030 & 0.005 \\
\hline
\end{tabular}

Goodness-of-fit of the model: adjusted $R^{2}=0.100 ; P$ value $=0.001$

late $\mathrm{H} / \mathrm{M}$. However, it is more likely that this association reflects that a longer acquisition time results in a higher number of counts and the allied improvement of count statistics. In particular, in patients with reduced myocardial uptake (i.e. heart failure patients), the higher signal-to-noise ratio for a longer acquisition ( $\geq 10 \mathrm{~min}$ in the present study) plays a pivotal role in the accurate assessment of late $\mathrm{H} / \mathrm{M}$. In addition, delay after injection was in high-risk subjects (late $\mathrm{H} / \mathrm{M}<1.4$ ), an independent predictor of late $\mathrm{H} / \mathrm{M}$. The negative correlation suggests that a longer acquisition time is associated with a lower late $\mathrm{H} / \mathrm{M}$.

However, in analogy to acquisition duration, it is more likely that this association reflects that a longer delay results in a lower number of counts and the allied deterioration of count statistics. In particular, in patients with reduced myocardial uptake (i.e. heart failure patients), the higher signal-to-noise ratio for a shorter delay after injection plays a pivotal role in the accurate assessment of late $\mathrm{H} / \mathrm{M}$.

The most well-validated influence on the measured late $\mathrm{H} /$ $\mathrm{M}$ is the collimator type. Because of the high-energy photons emitted by ${ }^{123} \mathrm{I}$, septal penetration affects estimation of the $\mathrm{H} / \mathrm{M}$ ratio in ${ }^{123} \mathrm{I}-\mathrm{MIBG}$ imaging with a low-energy (LE) collimator [21]. Medium-energy (ME) collimators have been shown to improve quantitative accuracy in ${ }^{123}$ I studies $[14,21,22]$. While these results would suggest that semiquantitative cardiac ${ }^{123}$ I-MIBG imaging might best be performed using ME collimators, there are practical limitations to such a recommendation. Almost all nuclear cardiology procedures are now performed on a multi-head gamma camera, and many dedicated dual-head cardiac cameras are not supplied with ME collimators (at least for SPECT).

Table 5 Multivariate analysis of clinical and acquisition related parameters as predictors of late $\mathrm{H} / \mathrm{M}$ for subjects with a late $\mathrm{H} / \mathrm{M}>2.0$ $(N=96)$

\begin{tabular}{llll}
\hline Variables & Coefficient $b$ & Standard error $b$ & P value \\
\hline $\begin{array}{l}\text { Constant } \\
\text { Duration of } \\
\text { acquisition }\end{array}$ & 0.022 & 1.376 & \\
\hline
\end{tabular}

Goodness-of-fit of the model: adjusted $R^{2}=0.013 ; P$ value $=0.347$
The precise impact of collimator choice on the prognostic value has not been evaluated yet. However, it seems feasible that the improved accuracy of the ME collimators will decrease the number of patients with an intermediate risk likelihood and thereby improving the prognostic accuracy of myocardial uptake parameters of ${ }^{123}$ I-MIBG. It is therefore important to establish the degree to which the collimator used affects prognostic utility of the $\mathrm{H} / \mathrm{M}$ measurement.

Rigorous and uniform analysis of cardiac ${ }^{123} \mathrm{I}$-MIBG parameters minimises inter-and intra-individual variation $[15,23]$. In the analysis of the entire population, numerous variables (LVEF, collimator type, duration of acquisition, NYHA classification and age) contributed to the prediction of $\mathrm{H} / \mathrm{M}$, but only two of these variables are under the control of the imager. Furthermore, the present results suggest that the severity of cardiac sympathetic neuronal dysfunction also modulates the impact of acquisition parameters on the $\mathrm{H} / \mathrm{M}$ determinations. For example, in the low-risk group $(\mathrm{H} / \mathrm{M}>2.0)$, none of the parameters had a meaningful impact on the numerical result, indicating that preserved myocardial uptake of ${ }^{123}$ I-MIBG can be reliably determined under widely different acquisition conditions. By comparison, considering user-controlled variables, assessment of high-risk subjects $(\mathrm{H} / \mathrm{M}<1.4)$ was affected by delay after injection, while the assessment of $\mathrm{H} / \mathrm{M}$ in the intermediate risk subjects was affected by the collimator employed. Standardisation therefore is most important in assessing patients with more severe disease, although in the present study the procedural variables only contributed a relatively small fraction of the overall variability in $\mathrm{H} / \mathrm{M}$ determinations.

Aging is associated with changes in the cardiovascular autonomic regulation, both under resting and stimulated conditions. At rest, elderly subjects show increased sympathetic and decreased parasympathetic activity as well as impaired arterial baroreflex function [24-34]. The negative correlation, although weak, between age and late $\mathrm{H} / \mathrm{M}$ is in line with the finding that sympathetic activity increases with age typically reflected by increased circulating catecholamine levels, and that it is associated with decreased myocardial uptake of ${ }^{123}$ I-MIBG, an observation previously reported by Somsen et al. [35] and Estorch et al [36].

${ }^{123}$ I-MIBG has been shown by individual centres to have both good reproducibility and acceptable variability, and to have prognostic value in CHF patients [3-11, 23, 37, 38]. These single-centre experiences, however, do not necessarily allow for extrapolation of the obtained results to other centres. In spite of this, quantitative thresholds are often implemented without inter-institutional validation. Because there are differences between centres in hardware, acquisition parameters and post-acquisition processing, the extrapolation to other centres, or generalisation of these single-centre findings, is not 
per se justified. Especially due to the lack of well-defined data sets, validation in each separate centre and between centres has not been possible.

Recently, a realistic 3D-gated cardiac phantom, the Amsterdam gated cardiac phantom (AGATE phantom), was developed and validated [39]. Such a phantom could be used as a tool for the validation in each separate centre and for standardisation between centres. However, a phantom can only partially simulate patient characteristics. Therefore, the phantom results obtained will give only an impression of repeatability and variability, but they do not necessarily reflect the accuracy of measurements in patients. Therefore, in addition to the phantom measurements, a set of reference patient studies should also be included in a validation of the technique [40]. Moreover, the results should be validated in each separate centre and monitored for reproducibility and consistency.

Several medications used to treat patients with heart failure may influence myocardial ${ }^{123}$ I-MIBG uptake. However, in our study the data on medication use were relatively complete, available for about $80 \%$ of the study subjects, so any further analysis could only be based on this subset. The problem with pursuing a medication analysis is that any effect on ${ }^{123}$ I-MIBG uptake is related to individual physiology and efficacy of treatment rather than on the technical attributes of the imaging, which was the main focus of this manuscript. In addition, the main manuscript already included results examining these effects, specifically that subjects that had events were less likely to be on $\beta$-blockers than those who did not have events [15]. A specific analysis of the effect of medication was not deemed appropriate to this manuscript. In addition, the use of medication that interferes with myocardial uptake of ${ }^{123}$ I-MIBG (such as tricyclic antidepressants), was not significant and did not warrant a separate analysis.

The primary limitation of the present study has already been noted, namely, that the largest influence on the H/M is cardiac disease status rather than image acquisition parameters. Although collimation and acquisition duration were independent predictors of late $\mathrm{H} / \mathrm{M}$, their individual contributions to measurement variance were $<10 \%$ each. Because of the retrospective nature of this multi-centre study, it was not possible to control for the effects of numerous variables that might have had undetected impact on late H/M. Studies using phantoms have already established the effect of collimator selection on $\mathrm{H} / \mathrm{M}$, and similar studies could be performed to examine the influence of count rate and total counts. Additional patient studies that included multiple acquisitions of different durations and times post-injection could establish the effect of these parameters on $\mathrm{H} / \mathrm{M}$ with greater clarity.

In conclusion, the limited standardisation in acquisition parameters reported in literature was also reflected in the results of this multi-centre study. A wide variety of collimators, delay after injection of ${ }^{123}$ I-MIBG to the start of the acquisition and acquisition durations were reported. In general, validation and standardisation require commitment and perseverance. Moreover, without proper validation and standardisation, the role myocardial ${ }^{123} \mathrm{I}-\mathrm{MIBG}$ in the clinical management of $\mathrm{CHF}$ will continue to be constrained. Without these requirements, the use of myocardial ${ }^{123}$ I-MIBG will be limited to a single centre research tool for understanding the physiology of myocardial sympathetic neuronal activity under different conditions and after interventions. With application of appropriate standardisation, myocardial ${ }^{123}$ I-MIBG imaging could become a routine procedure for evaluation of heart failure and other cardiac disease populations.

Conflict of interest statement/disclosures This study was funded by GE Healthcare.

Arnold Jacobson is employed by GE Healthcare.

None of the other authors report any relationships to disclose.

\section{References}

1. Sisson JC, Shapiro B, Meyers L, Mallette S, Mangner TJ, Wieland $\mathrm{DM}$, et al. Metaiodobenzylguanidine to map scintigraphically the adrenergic nervous system in man. J Nucl Med 1987;28:1625-36.

2. Kline RC, Swanson DP, Wieland DM, Thrall JH, Gross MD, Pitt $\mathrm{B}$, et al. Myocardial imaging in man with I-123 meta-iodobenzylguanidine. J Nucl Med 1981;22:129-32.

3. Merlet P, Valette H, Dubois-Rande JL, Moyse D, Duboc D, Dove $\mathrm{P}$, et al. Prognostic value of cardiac metaiodobenzylguanidine imaging in patients with heart failure. J Nucl Med 1992;33:471-7.

4. Merlet P, Benvenuti C, Moyse D, Pouillart F, Dubois-Rande JL, Duval AM, et al. Prognostic value of MIBG imaging in idiopathic dilated cardiomyopathy. J Nucl Med 1999;40:917-23.

5. Momose M, Kobayashi H, Iguchi N, Matsuda N, Sakomura Y, Kasanuki H, et al. Comparison of parameters of 123I-MIBG scintigraphy for predicting prognosis in patients with dilated cardiomyopathy. Nucl Med Commun 1999;20:529-35.

6. Cohen-Solal A, Esanu Y, Logeart D, Pessione F, Dubois C, Dreyfus G, et al. Cardiac metaiodobenzylguanidine uptake in patients with moderate chronic heart failure: relationship with peak oxygen uptake and prognosis. J Am Coll Cardiol 1999; 33:759-66.

7. Wakabayashi T, Nakata T, Hashimoto A, Yuda S, Tsuchihashi K, Travin MI, et al. Assessment of underlying etiology and cardiac sympathetic innervation to identify patients at high risk of cardiac death. J Nucl Med 2001;42:1757-67.

8. Kasama S, Toyama T, Kumakura H, Takayama Y, Ichikawa S, Suzuki $T$, et al. Spironolactone improves cardiac sympathetic nerve activity and symptoms in patients with congestive heart failure. J Nucl Med 2002;43:1279-85.

9. Yamada T, Shimonagata T, Fukunami M, Kumagai K, Ogita H, Hirata $\mathrm{A}$, et al. Comparison of the prognostic value of cardiac iodine-123 metaiodobenzyl-guanidine imaging and heart rate variability in patients with chronic heart failure: a prospective study. J Am Coll Cardiol 2003;41:231-8. 
10. Kyuma M, Nakata T, Hashimoto A, Nagao K, Sasao H, Takahashi $\mathrm{T}$, et al. Incremental prognostic implications of brain natriuretic peptide, cardiac sympathetic nerve innervation, and noncardiac disorders in patients with heart failure. J Nucl Med 2004;45: 155-63.

11. Nakata T, Wakabayashi T, Kyuma M, Takahashi T, Tsuchihashi K, Shimamoto K. Cardiac metaiodobenzylguanidine activity can predict the long-term efficacy of angiotensin-converting enzyme inhibitors and/or beta-adrenoceptor blockers in patients with heart failure. Eur J Nucl Med Mol Imaging 2005;32:186-94.

12. Arora R, Ferrick KJ, Nakata T, Kaplan RC, Rozengarten M, Latif F, et al. I-123 MIBG imaging and heart rate variability analysis to predict the need for an implantable cardioverter defibrillator. $\mathrm{J}$ Nucl Cardiol 2003;10:121-31.

13. Paul M, Schafers M, Kies P, Acil T, Schafers K, Breithardt G, et al. Impact of sympathetic innervation on recurrent life-threatening arrhythmias in the follow-up of patients with idiopathic ventricular fibrillation. Eur J Nucl Med Mol Imaging 2006;33:866-70.

14. Verberne HJ, Feenstra C, de Jong WM, Somsen GA, van EckSmit BL, Busemann Sokole E. Influence of collimator choice and simulated clinical conditions on 123I-MIBG heart/mediastinum ratios: a phantom study. Eur J Nucl Med Mol Imaging 2005; 32:1100-7.

15. Agostini D, Verberne HJ, Povinec P, Burchert W, Sambuceti G, Knuuti J, et al. Utility of ${ }^{123}$ I-MIBG scintigraphy in subjects with heart failure for assessment of risk for a major cardiac event: a European multi-center study. Circulation 2006;114 Suppl II:574.

16. Suwa M, Otake Y, Moriguchi A, Ito T, Hirota Y, Kawamura K, et al. Iodine-123 metaiodobenzylguanidine myocardial scintigraphy for prediction of response to beta-blocker therapy in patients with dilated cardiomyopathy. Am Heart J 1997;133:353-8.

17. Estorch M, Flotats A, Serra-Grima R, Mari C, Prat T, Martin JC, et al. Influence of exercise rehabilitation on myocardial perfusion and sympathetic heart innervation in ischaemic heart disease. Eur J Nucl Med 2000;27:333-9.

18. Parthenakis FI, Prassopoulos VK, Koukouraki SI, Zacharis EA, Diakakis GF, Karkavitsas NK, et al. Segmental pattern of myocardial sympathetic denervation in idiopathic dilated cardiomyopathy: relationship to regional wall motion and myocardial perfusion abnormalities. J Nucl Cardiol 2002;9:15-22.

19. Lanza GA, Giordano A, Pristipino C, Calcagni ML, Meduri G, Trani $\mathrm{C}$, et al. Abnormal cardiac adrenergic nerve function in patients with syndrome $\mathrm{X}$ detected by [123I]metaiodobenzylguanidine myocardial scintigraphy. Circulation 1997;96:821-6.

20. Wichter T, Matheja P, Eckardt L, Kies P, Schafers K, SchulzeBahr E, et al. Cardiac autonomic dysfunction in Brugada syndrome. Circulation 2002;105:702-6.

21. Inoue Y, Suzuki A, Shirouzu I, Machida T, Yoshizawa Y, Akita F, et al. Effect of collimator choice on quantitative assessment of cardiac iodine 123 MIBG uptake. J Nucl Cardiol 2003;10:623-32.

22. Dobbeleir AA, Hambye AS, Franken PR. Influence of highenergy photons on the spectrum of iodine-123 with low- and medium-energy collimators: consequences for imaging with 123Ilabelled compounds in clinical practice. Eur J Nucl Med 1999; 26:655-8.

23. Somsen GA, Verberne HJ, Fleury E, Righetti A. Normal values and within-subject variability of cardiac I-123 MIBG scintigraphy in healthy individuals: implications for clinical studies. J Nucl Cardiol 2004;11:126-33.

24. Byrne EA, Fleg JL, Vaitkevicius PV, Wright J, Porges SW. Role of aerobic capacity and body mass index in the age-associated decline in heart rate variability. J Appl Physiol 1996;81:743-50.

25. Colosimo A, Giuliani A, Mancini AM, Piccirillo G, Marigliano V. Estimating a cardiac age by means of heart rate variability. Am J Physiol Heart Circ Physiol 1997;273:H1841-H1847.

26. Craft N, Schwartz JB. Effects of age on intrinsic heart rate, heart rate variability, and AV conduction in healthy humans. Am J Physiol Heart Circ Physiol 1995;268:H1441-H1452.

27. Esler MD, Thompson JM, Kaye DM, Turner AG, Jennings GL, Cox HS, et al. Effects of aging on the responsiveness of the human cardiac sympathetic nerves to stressors. Circulation 1995; 91:351-8.

28. Kingwell BA, Thompson JM, Kaye DM, McPherson GA, Jennings GL, Esler MD. Heart rate spectral analysis, cardiac norepinephrine spillover, and muscle sympathetic nerve activity during human sympathetic nervous activation and failure. Circulation 1994;90:234-40.

29. Laitinen T, Hartikainen J, Vanninen E, Niskanen L, Geelen G, Lansimies E. Age and gender dependency of baroreflex sensitivity in healthy subjects. J Appl Physiol 1998;84:576-83.

30. Tsuji H, Venditti FJ Jr, Manders ES, Evans JC, Larson MG, Feldman CL, et al. Determinants of heart rate variability. J Am Coll Cardiol 1996;28:1539-46.

31. Shimada K, Kitazumi T, Sadakane N, Ogura H, Ozawa T. Agerelated changes of baroreflex function, plasma norepinephrine, and blood pressure. Hypertension 1985;7:113-7.

32. Cowie MR, Rawles JM. A modified method of quantifying the carotid baroreceptor-heart rate reflex in man: the effect of age and blood pressure. Clin Sci (Lond) 1989;77:223-8.

33. Iwase S, Mano T, Watanabe T, Saito M, Kobayashi F. Age-related changes of sympathetic outflow to muscles in humans. J Gerontol 1991;46:M1-M5.

34. Randall O, Esler M, Culp B, Julius S, Zweifler A. Determinants of baroreflex sensitivity in man. J Lab Clin Med 1978;91:514-9.

35. Somsen GA, Borm JJ, Dubois EA, Schook MB, van der Wall EE, van Royen EA. Cardiac 123I-MIBG uptake is affected by variable uptake in reference regions: implications for interpretation in clinical studies. Nucl Med Commun 1996;17:872-6.

36. Estorch M, Carrio I, Berna L, Lopez-Pousa J, Torres G. Myocardial iodine-labeled metaiodobenzylguanidine 123 uptake relates to age. J Nucl Cardiol 1995;2:126-32.

37. Merlet P, Pouillart F, Dubois-Rande JL, Delahaye N, Fumey R, Castaigne A, et al. Sympathetic nerve alterations assessed with 123IMIBG in the failing human heart. J Nucl Med 1999;40: 224-31.

38. Agostini D, Belin A, Amar MH, Darlas Y, Hamon M, Grollier G, et al. Improvement of cardiac neuronal function after carvedilol treatment in dilated cardiomyopathy: a 123I-MIBG scintigraphic study. J Nucl Med 2000;41:845-51.

39. Visser JJ, Busemann Sokole E, Verberne HJ, Habraken JB, van de Stadt HJ, Jaspers JE, et al. A realistic 3-D gated cardiac phantom for quality control of gated myocardial perfusion SPET: the Amsterdam gated (AGATE) cardiac phantom. Eur J Nucl Med Mol Imaging 2004;31:222-8.

40. Britton KE, Busemann Sokole E. COST B2: why and wherefore. Eur J Nucl Med 1992;19:563-8. 